[5] Wang L, Turner MO, Elwood RK, Schulzer M, FitzGerald JM. A meta-analysis of the effect of Bacille Calmette Guérin vaccination on tuberculin skin test measurements. Thorax. 2002 Sep;57(9):804-9.

[6] Araujo Z, de Waard JH, de Larrea CF, Borges R, Convit J. The effect of Bacille Calmette-Guérin vaccine on tuberculin reactivity in indigenous children from communities with high prevalence of tuberculosis. Vaccine. 2008 Oct 16;26(44):5575-81.

[7] Farhat M, Greenaway C, Pai M, Menzies D. False-positive tuberculin skin tests: what is the absolute effect of BCG and non-tuberculous mycobacteria? Int J Tuberc Lung Dis. 2006 Nov;10(11):1192-204.

[8] Abdel-Samea S, Ismail Y, Fayed S, Mohammad A. Comparative study between using QuantiFERON and tuberculin skin test in diagnosis of Mycobacterium tuberculosis infection. EJCT. 2013;62:137-43.

Acknowledgement: The Scleroderma Research Group and the Faculty of Medicine, Khon Kaen University (Grant Number GR60101)

Disclosure of Interests: None declared

DOI: 10.1136/annrheumdis-2019-eular.1456

\section{FRI0348 USE OF INTRAVENOUS IMMUNOGLOBULIN THERAPY IN PATIENTS WITH SYSTEMIC SCLEROSIS: A SPANISH MULTICENTER EXPERIENCE}

Jose Luis TANDAIPAN JAIME ${ }^{1}$, Alfredo Guillén del Castillo², Carmen Pilar Simeón-Aznar ${ }^{2}$, Patricia Carreira ${ }^{3}$, J. Narváez ${ }^{4}$, Jose M. Pego-Reigosa ${ }^{5}$, Rosario Garcia de Vicuna ${ }^{6}$, Anna Pros ${ }^{7}$, Carlos De la Puente Bujidos ${ }^{8}$, Vera OrtizSantamaria ${ }^{9}$, Belén Atienza-Mateo ${ }^{10}$, J Lluch Pons ${ }^{4}$, Manuel Rubio-Rivas ${ }^{11}$, Ricardo Blanco ${ }^{10}$, Ivan Castellvi ${ }^{12}$, Rheumatology. ${ }^{1}$ Hospital Universitari Mutua de Terrassa, Rheumatology, Terrassa, Spain; ${ }^{2}$ Hospital Universitario Vall d'Hebron, Unit of Autoimmune Diseases, Department of Internal Medicine, Barcelona, Spain; ${ }^{3}$ Hospital Universitario 12 de Octubre, Rheumatology, Madrid, Spain; ${ }^{4}$ Hospital Universitari Bellvitge, Rheumatology, Barcelona, Spain; ${ }^{5}$ Hospital Meixoeiro, Rheumatology, Vigo, Spain; ${ }^{6}$ HOSPITAL UNIVERSITARIO DE LA PRINCESA, Rheumatology, Madrid, Spain; ${ }^{7}$ HOSPITAL DEL MAR, Rheumatology, Barcelona, Spain; ${ }^{8}$ Hospital Universitario Ramón y Cajal, Rheumatology, Madrid, Spain; ${ }^{9}$ Granollers General Hospital, Rheumatology, Granollers, Spain; ${ }^{10} \mathrm{H}$. Marques de Valdecilla, Rheumatology, Santander, Spain; ${ }^{11}$ Hospital Universitari Bellvitge, Unit of Autoimmune Diseases, Barcelona, Spain; ${ }^{12}$ Hospital Universitario de la Santa Creu i Sant Pau, Rheumatology, Barcelona, Spain

Objectives: To describe the efficacy of intravenous immunoglobulin (IVIG) therapy in different organic conditions of Systemic Sclerosis (SSc).

Methods: Retrospective multicenter observational study that enrolled patients with SSc treated with IVIG. We collected epidemiological data, SSc complications, treatments and functional tests. Regarding IVIG treatment we recorded the reason to use, number of cycles, and the clinical efficacy at the end of the last IVIG cycle were collected at investigator's discretion. For the comparison of variables, the Chi-square, Fisher's $F$ test and the $T$ test was used.

Results: 41 patients (83\% women) were recruited, with a mean age of $58 \pm 18.2$ years old. The age of diagnosis was $48 \pm 8$ years old. The diffuse cutaneous SSc was the most frequent in the sample (61\%) and $24 / 41$ had Overlap syndrome (49\% myositis). Regarding the different SSc complications in treated patients the most frequent were digestive involvement, arthritis and interstitial lung disease $(78 \%, 73 \%$, and $63 \%$ respectively). $12 \%$ of patients developed cancer and $25 \%$ died during the follow-up. The most frequent indication IVIG was myositis $(51 \%)$ followed by cutaneous $(17 \%)$. The mean of cycles was $10.37 \%$ of patients had previously undergone treatment with biological therapy, being RTX the most used therapy. $80 \%$ of patients had a history of use with corticosteroid therapy. When evaluating the degree of skin involvement (mRSS) patients showed a significant improvement of $-2.89 \pm 5.2(p<0.03)$ at the end of the follow-up. Indeed we observed better results in the groups of patients with myositis. No differences were observed in the\% FVC or\% DLCO outcomes during the follow-up. However, when we compared patients with or without overlap syndrome we found differences in\%FVC values at the beginning of the study that were not present at the end of the follow-up. Patients with antiScl70 seemed to have less response to IVIG therapy.

Conclusion: Our results suggest that IVIG can be useful for the management of some conditions in specific profiles of patients with SSc.
Prospective studies and randomized clinical trials are necessary to establish the efficacy and safety of IVIG to treat the different conditions of SSc.

\begin{tabular}{lccc}
\hline & IVIG $\mathbf{N}=\mathbf{4 1}(\%)$ & Difuse $\mathbf{n = 2 5}(\%)$ & Limited $\mathbf{n = 1 6 ( \% )}$ \\
\hline Women & $34(83)$ & $21(84)$ & $13(81)$ \\
Age & $58 \pm 18$ & & \\
Overlap & $24(59)$ & $11(44)$ & $13(81)$ \\
Clinical manifestations & & & \\
Joint & $30(73)$ & $22(88)$ & $8(50)$ \\
Muscular & $30(73)$ & $16(64)$ & $14(88)$ \\
Reflux GE & $32(78)$ & $20(95)$ & $12(75)$ \\
Interstitial lung disease & $26(63)$ & $16(64)$ & $10(63)$ \\
Pulmonary hypertension & $5(12)$ & $2(8)$ & $3(19)$ \\
\hline
\end{tabular}

\begin{tabular}{lcccc}
\hline & myositis & Overlap & AntiScl70 & $\begin{array}{c}\text { PM/ } \\
\text { Scl }\end{array}$ \\
\hline $\begin{array}{lccc}\text { Initial } \\
\text { mRss }\end{array}$ & $16 \pm 12$ & $13 \pm 11$ & $29 \pm 9$ & 15 \\
Final & & & \pm 10 \\
mRss & $12 \pm 12$ & $7 \pm 7$ & $32 \pm 7$ & 13 \\
Initial FVC & $68 \pm 25$ & $64 \pm 24$ & $56 \pm 23$ & \pm 15 \\
Final FVC & $73 \pm 26$ & $72 \pm 25$ & $58 \pm 20$ & 60 \\
Initial & & & & \pm 13 \\
DLCO & $56 \pm 16$ & $56 \pm 17$ & $55 \pm 16$ & \pm 18 \\
Final & & & & 49 \\
DLCO & $68 \pm 25$ & $71 \pm 24$ & $45 \pm 12$ & \pm 13 \\
\hline
\end{tabular}

Disclosure of Interests: Jose Luis TANDAIPAN JAIME: None declared, Alfredo Guillén del Castillo : None declared, Carmen Pilar Simeón-Aznar: None declared, Patricia Carreira: None declared, J. Narváez Consultant for: Bristol-Myers Squibb, Jose M Pego-Reigosa: None declared, Rosario Garcia de Vicuna Grant/research support from: Abbvie, BMS, Lilly, MSD, Novartis, Roche, Consultant for: Biogen, BMS, Mylan, Pfizer, Sanofi and Sandoz, Speakers bureau: BMS, Pfizer, Lilly, Sandoz, Anna Pros: None declared, Carlos De la Puente Bujidos: None declared, Vera Ortiz-Santamaria Speakers bureau: GSK, Roche, Pfizer, MSD, Belén Atienza-Mateo: None declared, J Lluch Pons : None declared, Manuel Rubio-Rivas: None declared, Ricardo Blanco Grant/research support from: Abbvie, MSD, and Roche, Consultant for: Abbvie, Pfizer, Roche, Bristol-Myers, Janssen, Speakers bureau: Abbvie, Pfizer, Roche, Bristol-Myers, Janssen, Ivan Castellví Consultant for: I received fees less than 5000USD as a consultant for Kern and Actelion, Paid instructor for: I received fees less than 2000USD as a instructor for Boehringer -Ingelheim, Novartis and Gebro, Speakers bureau: ND DOI: 10.1136/annrheumdis-2019-eular.2762

\section{FRI0349 RELATIONSHIPS BETWEEN BODY COMPOSITION AND NAILFOLD VIDEOCAPILLAROSCOPY PATTERNS IN SYSTEMIC SCLEROSIS PATIENTS}

Veronica Tomatis, Sabrina Paolino, Alberto Sulli, Emanuele Gotelli,

Andrea Casabella, Francesco Cattelan, Carlotta Schenone, Carmen Pizzorni, Elisa Alessandri, Maurizio Cutolo. IRCCS San Martino Polyclinic Hospital, Genoa, Italy, Research Laboratory and Academic Division of Clinical Rheumatology, Department of Internal Medicine, University of Genova, genoa, Italy

Background: Systemic sclerosis (SSc) is a chronic autoimmune disease, characterized by microvascular damage and progressive fibrosis. Among clinical complications, abnormal body composition and sarcopenia have been reported in SSc patients(1,2). Nailfold videocapillaroscopy (NVC) is a safe diagnostic tool to assess microvascular progressive damage and may predict severe organ involvement in $\mathrm{SSc}(3)$.

Objectives: The aim of this study was to evaluate body composition in SSc patients and assess possible differences between patients with specific NVC patterns of microangiopathy.

Methods: 38 patients (6 men and 32 women) fulfilling ACR 2013 criteria for SSc underwent NVC to assess their NVC patterns ("Early", "Active" and "Late" pattern)(4) and DXA to evaluate body composition(5). In particular we analyzed: total mass, total lean mass, total fat mass, bone 
mineral content(BMC), and bone mineral density(BMD) in seven body areas(head, upper limbs, lower limbs, trunk, spine, ribs, pelvis). Sarcopenia was diagnosed in patients with reduced skeletal muscle index (RSMI) below $5.45 \mathrm{Kg} / \mathrm{m}^{2}$ for females and $7.25 \mathrm{Kg} / \mathrm{m}^{2}$ for males(6). Statistical analysis was performed by non parametric tests.

Results: The mean age of patients was $64 \pm 11$ years, mean disease duration $19.2 \pm 7.6$ years, mean Rodnan skin score(mRSS) $11.5 \pm 9.3$, and mean RSMI $6.3 \pm 1.05 \mathrm{~g} / \mathrm{cm}^{2}$. All the patients showed a NVC "scleroderma pattern": in particular 15 patients showed the "Late" pattern, 15 patients the "Active" pattern and 8 patients the "Early" NVC pattern. The "Late" NVC pattern group comparing to "Early/Active" group showed significantly lower total mass $(58287 \pm 8217$ vs $67238 \pm 11437$ gr, $p=0.01)$, lean mass $(35249 \pm 3646$ vs $41230 \pm 7954 \mathrm{gr}, \mathrm{p}=0.05)$, $\mathrm{RSMI}(5.8 \pm 0.92$ vs $6.6 \pm 1.02 \mathrm{~g} /$ $\left.\mathrm{cm}^{2}, \mathrm{p}=0.02\right), \mathrm{BMC}(1839 \pm 339$ vs $2183 \pm 502 \mathrm{gr}, \mathrm{p}=0.04)$, trunk $\mathrm{BMD}(0.70$ \pm 0.12 vs $\left.0.87 \pm 0.13 \mathrm{~g} / \mathrm{cm}^{2}, \mathrm{p}=0.05\right)$ and spine $\operatorname{BMD}(0.91 \pm 0.17$ vs 1.08 $\pm 0.18 \mathrm{~g} / \mathrm{cm}^{2}, p=0.008$ ). No statically significant difference between the two group was observed regarding total fat mass, total body BMD and BMD at upper limbs, lower limbs, head, ribs and pelvis. Interestingly, 24\% of SSc patients were found affected by sarcopenia, and the most of sarcopenic patients showed the "Late" NVC pattern(67\%). Comparing age, disease duration, mRSS between sarcopenic and non sarcopenic patients there was no difference between the groups, but sarcopenic patients presented a statistically significant lower $\operatorname{BMI}(p=0.02)$.

Conclusion: This study demonstrates in SSc patients a relationship between a more severe microvascular damage ("Late" SSc pattern) and the body composition, characterized by lower weight, total lean mass, bone mineral content and sarcopenia, without any significant variation in total fat mass. These clinical conditions seem not to be associated with severity of skin involvement and/or disease duration.

\section{REFERENCE:}

[1] Caimmi C, et al. Clinical Rheumatology 2018;37:987-997.2. Thais FM, et al. Clin Rheumatol 2013:32:1037-44.3.Smith V, et al. J Rheumatol. 2013;40:2023-8.4.Cutolo M, et al. J Rheumatol 2000;27:155-60.5. Haarbo J, et al. Clin Physiol 1991;11:331-41.6.Baumgartner RN, et al. Am J Epidemiol 1998;147:755-63.

Disclosure of Interests: None declared

DOI: 10.1136/annrheumdis-2019-eular.6807

\section{FRI0350 THE FREQUENCY OF LOW MINERAL DENSITY, FALLS AND FRACTURES IN PATIENTS WITH SYSTEMIC SCLEROSIS}

Olga Dobrovolskaya, Nikolay Demin, Oxana Desinova, Natalia Toroptsova. V.A Nasonova Research Institute of Rheumatology, Moscow, Russian Federation

Background: Systemic sclerosis (SSc) is a severe connective tissue disorder causing vascular, immune, and fibrotic changes in the skin and internal organs. Patients with SSc may have an increased risk of osteoporosis (OP) and fractures due to a chronic inflammatory state, latent malabsorption or malnutrition, immobilization, and use of corticosteroid therapy.

Objectives: to determine the frequency of low mineral density, falls, low energy fractures and 10-year probability of new fracture in patients with SSc.

Methods: 191 patients with SSc were enrolled in the study: 160 women (mean age $51 \pm 13 \mathrm{yrs}$ ), among them 107 postmenopausal, and 31 men (mean age $53 \pm 14 \mathrm{yrs}$ ). Bone mineral density (BMD) was measured at lumbar spine (LS), femoral neck (FN) and total hip (TH) by dual energy X-ray absorptiometry (DXA, Hologic 4500A). BMD decreasing grade was determined in accordance to $\mathrm{WHO}$ criteria. All patients were interviewed on a special questionnaire and assessment of 10-year probability of new fracture by FRAX $^{\oplus}$ was performed. Vitamin D level was measured in 104 patients.

Results: Low BMD was found in $68 \%$ women and $55 \%$ men: osteopenia in $30 \%$ and $32 \%$ and OP in $38 \%$ (21\% in reproductive age and $50 \%$ in postmenopausal) and $23 \%$, respectively. BMD in LS, FN and TH associated with body mass index $(r=0,3, p=0,030 ; r=0,41, p=0,0027 ; r=0,49$, $\mathrm{p}=0,0002$, respectively) and duration of postmenopausal period in women $(r=-0,56, p=0,023 ; r=-0,66, p=0,006 ; r=-0,63, p=0,009$, respectively). BMD of LS and FN correlated with age $(r=-0,22, p=0,045 ; r=-0,23, p=0,016$, respectively), duration of $S S c(r=-0,32, p=0,037 ; r=-0,31, p=0,046$, respectively), glucocorticoid cumulative dose for LS only $(r=-0,31, p=0,024)$. Mean 25(OH)D level was $19,83 \pm 11,06 \mathrm{ng} / \mathrm{ml}$. Normal vitamin D level had $9 \%$ of SSc patients. No correlation between BMD and 25(OH)D level was found.
$46(24 \%)$ patients reported falls in the year prior to the interview, among them in 2 patients the fall led to fracture. A total of $48(25 \%)$ patients had low energy fractures in the past, among them $8(4 \%)$ of women had two or more fractures. Frequency of low energy fractures was $35 \%$, $8 \%$ and $25 \%$ among postmenopausal women, women of reproductive age and men, respectively. The mean age at which the fracture occurred was $55 \pm 11$ yrs. in postmenopausal women, $30 \pm 12$ yrs. in young women and $60 \pm 12$ yrs. in men. The most frequent were the fractures of distal forearm and vertebrae: $13(7 \%)$ and 26 (14\%) patients, respectively. Five patients each $(3 \%)$ had ankle and humerus neck fractures and 7 - other localizations. Nobody reported the fracture of the proximal femur. Patients with abnormal BMD (OP or osteopenia) had a risk of falls and low energy fractures more than 2 times higher than patients with normal BMD (OR $2.93[95 \%$ Cl 1.11; 8.01], $p=0,016$ and OR $2.58[95 \% \mathrm{Cl}$ $1.04 ; 6.6], p=0,025$, respectively). 10-year probability of any major osteoporotic fracture was $18.4 \pm 9.6 \%$ in women and $9.7 \pm 8.6 \%$ in men and of hip fracture $-3.5 \pm 3.7 \%$ and $1.5 \pm 3.9 \%$, respectively. Among all patients, $55 \%$ of women and $4 \%$ of men had a high risk of subsequent fractures using the FRAX ${ }^{\circledR}$ algorithm.

Conclusion: Low BMD was diagnosed in $68 \%$ of women and $55 \%$ of men with SSc. The correlations between BMD and age, body mass index, the duration of postmenopause were revealed. Additionally, we found associations with risk factors related to the disease itself: disease duration and glucocorticoid cumulative dose. Reduced BMD was associated with an increased risk of falls and fractures. $55 \%$ of women and $4 \%$ of men had a high risk of further fractures.

Disclosure of Interests: Olga Dobrovolskaya: None declared, Nikolay Demin: None declared, Oxana Desinova: None declared, Natalia Toropt sova Speakers bureau: Amgen, Lilly DOI: 10.1136/annrheumdis-2019-eular.3125

\section{FRI0351 DISTINCTION BETWEEN TELANGIECTASIA SECONDARY TO CONNECTIVE TISSUE DISEASE AND CUTANEOUS COLLAGENOUS VASCULOPATHY}

Noreen Walsh ${ }^{1}$, Phillip Moss ${ }^{2}$, Thaiyen Ly ${ }^{1}$, Sylvia Pasternak ${ }^{1}$, Peter Green ${ }^{1}$ Chris Gallant ${ }^{1}$, Mary Lou Baxter ${ }^{1}$, Colleen Kelly ${ }^{1}$, Ariel Burns ${ }^{1}$, Kerri Purdy ${ }^{1}$, Elana Murphy ${ }^{1}$, John Hanly ${ }^{1} .{ }^{1}$ Queen Elizabeth II Health Sciences Center and Dalhousie University, Pathology, Halifax, Nova Scotia, Canada; ${ }^{2}$ Queen Elizabeth II Health Sciences Center, Halifax, Canada

Background: Cutaneous collagenous vasculopathy (CCV), a recently described, rare, superficial dermal microangiopathy of unknown etiology, shares clinical and histopathological features in common with cutaneous lupus erythematosus and dermatomyositis. Fewer than 50 cases have been reported in the literature. Concurrence of CCV and connective tissue diseases (CTD) may present a diagnostic quandary.

Objectives: To determine whether CCV cases at our center were associ ated with CTD and to identify distinguishing features between CCV and cutaneous manifestations of CTD.

Methods: The laboratory information system at a single academic health care center (2000-2018) was searched to identify cases with a diagnosis of CCV. All pathological material and clinical charts were reviewed. The demographic, clinical and pathological data were documented.

Results: We identified 6 cases of CCV (4 female, 2 male; median age 57 years). Clinically, a telangiectatic eruption was present in all patients, affecting the lower limbs and other sites $(\mathrm{N}=5)$ and the abdomen and arms $(\mathrm{N}=1)$. All patients had been seen by a dermatologist and 3 by a rheumatologist. A concurrent CTD was present in 2 cases; Sjogren's syndrome $(\mathrm{N}=1)$ and undifferentiated connective tissue disease $(\mathrm{N}=1)$. In both, the clinical differential diagnosis included CCV and cutaneous involvement by the CTD. In all 6 cases, histopathological examination revealed a non-inflammatory vasculopathy, with PAS-positive, diastase resistant, hyaline thickening of ectatic superficial capillary walls, and loss of pericytes. These hallmarks of $\mathrm{CCV}$ excluded skin disease attributable to CTD in the two relevant cases.

Conclusion: Concurrence of $\mathrm{CCV}$ and $\mathrm{CTD}$, though uncommon, presents a diagnostic challenge. The clinical distribution of the CCV eruption, favouring the lower limbs, and its non-inflammatory character histopathologically distinguish it from cutaneous involvement by a CTD.

Disclosure of Interests: Noreen Walsh: None declared, Phillip Moss: None declared, ThaiYen Ly: None declared, Sylvia Pasternak: None declared, Peter Green: None declared, Chris Gallant: None declared, Mary Lou Baxter: None declared, Colleen Kelly: None declared, Ariel Burns: None declared, Kerri Purdy: None declared, Elana Murphy: None declared, John Hanly Consultant for: Eli Lilly Canada.

DOI: 10.1136/annrheumdis-2019-eular.1832 